\title{
Interprofessional sepsis education module: a pilot study
}

\author{
Han-Oh Chung, MD*; Damien Medina, $\mathrm{MD}^{\dagger}$; Alison Fox-Robichaud, MSc, MD*
}

\section{ABSTRACT}

Although there is an increasing emphasis on interprofessional collaboration for safer health care systems, there remains a paucity of opportunities for postgraduate trainees to engage in formal interprofessional education (IPE). Current opportunities for interprofessional learning, such as simulation sessions, typically do not provide true IPE because they often utilize actors or confederates as support staff, making residents the only stakeholders in the education experience.

Here, we describe a flexible educational module designed to provide genuine IPE for physicians, nurses, and respiratory therapists. We outline how simulation, feedback, and group discussions can be used to teach interprofessional team communication, collaboration, and crew resource management skills-while, at the same time, also teaching a highly relevant medical topic (sepsis management) and thus resulting in learner engagement and motivation.

\section{RÉSUMÉ}

Certes, on insiste de plus en plus sur la collaboration interprofessionnelle pour développer des systèmes de soins de santé plus sûrs, mais les possibilités de formation interprofessionnelle structurée (FIS) pour les stagiaires de cycles supérieurs se font rares. Les offres actuelles d'apprentissage interprofessionnel, par exemple les séances de simulation, ne constituent pas en général de véritable FIS étant donné que les responsables comptent souvent sur les services d'acteurs ou de compères pour agir comme personnel de soutien, ce qui fait des résidents les seuls intervenants actifs dans l'expérience de formation.
Sera décrit ici un module de formation souple, conçu pour offrir aux médecins, au personnel infirmier et aux inhalothérapeutes une véritable FIS. Les auteurs montreront comment la simulation, les rétroactions et les discussions de groupe peuvent servir à l'enseignement de la communication et de la collaboration entre équipes professionnelles ainsi qu'à l'acquisition d'habiletés de gestion des ressources en équipe, tout en permettant l'étude d'un sujet médical très pertinent, soit la prise en charge de la sepsie, ce qui suscite intérêt et motivation des apprenants.

Keywords: Simulation, interprofessional education, sepsis

\section{BACKGROUND}

Traditionally, in postgraduate medical education, each specialty is taught in isolation. This results in minimal emphasis on interprofessional education (IPE), and this deficiency can act as a hidden curriculum that negatively affects health care team structures. We identified an opportunity to address IPE while teaching best practice sepsis management guidelines.

\section{RATIONALE}

There is increasing evidence that improved communication and collaboration by interprofessional teams lead to better care. ${ }^{1}$ Technology-enhanced simulation is beneficial in improving team dynamics during medical crises through practicing teamwork in a controlled, adaptable environment. ${ }^{2}$ The merits of IPE using simulation have been shown to break down unhelpful

From the *Division of Critical Care, McMaster University, Hamilton, ON; and tDepartment of Medicine/Critical Care, Niagara Health System, St. Catharines, ON.

Correspondence to: Dr. Alison Fox-Robichaud, David Braley Research Institute C5-106, 237 Barton Street East, Hamilton, ON L8L 2X2; Email: afoxrob@mcmaster.ca 


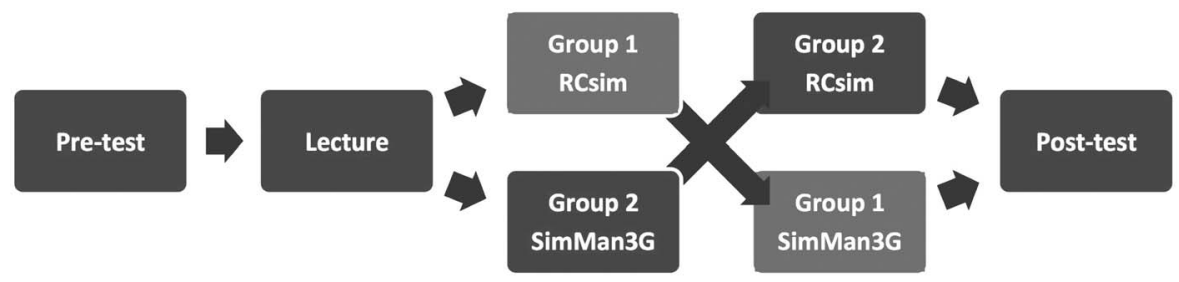

Figure 1. Description of group arrangement and scheduling.

social constructs of hierarchy and silo mentality in highstakes interprofessional situations, such as in operating rooms and during cardiac resuscitation. ${ }^{3-5}$

Sepsis management is intrinsically interprofessional, with various health care providers involved at many levels. It is also high-stakes; hospitalized patients with sepsis have a high mortality rate and account for significant health care expenses. Fortunately, sepsis outcomes are highly influenced by educational interventions that improve guideline compliance. ${ }^{6}$ This module that we designed fulfills the need of both practical sepsis education and IPE.

\section{DESCRIPTION OF INNOVATION}

We designed a pilot program for McMaster trainees that was delivered over two sessions in February and April 2012. Twenty-two participants enrolled: 15 residents from the Royal College of Physicians and Surgeons of Canada Emergency Medicine (RCPS-EM) and from the College of Family of Physicians of Canada (CFPC-EM), and internal medicine training programs, 4 emergency nurses (registered nurses [RNs]), and 2 respiratory therapists (RTs). Our aim was to create an educational resource that addressed 1) knowledge, through testenhanced learning on the sepsis guidelines, and 2) behaviour, through using simulation to provide a practical experience of sepsis management and interprofessional teamwork.

Participants were recruited on a first-come basis through emails from the residents' respective program offices, and clinical educators (in the case of RNs and RTs). Each session for participants started with a pretest and ended with a posttest to characterize baseline knowledge and learning. A 1-hour case-based interactive presentation on sepsis management was given prior to simulation practice. Both the test and presentation were peer-reviewed by content experts from the RCPSC for content validity and relevance regarding pathophysiology, and for the diagnosis and management of sepsis. After the presentation, the group was divided in half in a manner intended to optimize the distribution of the interprofessional members. Each group went through 2 hours of simulation, 1 hour of which involved a high-fidelity simulator, and the other hour of which involved a virtual patient simulator (Figure 1).

The high-fidelity mannequin (Laerdal SimMan 3G) was used to address interprofessional team behavior while attending to a patient with progressive septic shock. The scenarios included acute peritonitis, meningitis, and pneumonia. "Distractors," such as serious arrhythmias, were used to necessitate the need for efficient crew resource management of all interprofessional members. Each team was composed of an $\mathrm{RN}$, an RT, a physician team leader, and 1-2 other physician helpers. When not actively in the simulation, other participants learned through observation and participating in the provision of feedback. Each scenario ended with video-enhanced, semi-structured feedback. The feedback focused on the proper medical management of sepsis resuscitation and process of interprofessional teamwork, communication, and collaboration.

The second simulation used a virtual patient simulator (RCSim, RCPSC) with a scenario of urosepsis and shock. Participants learned in a constructivist fashion, through facilitated discussion as the scenario progressed. The simulation ended with a semi-structured feedback, focusing on management prioritization, decision-making processes of the various interprofessional peers, and reflections on experiences.

The program ended with a quantitative evaluation of the program that also included the option to provide general free-text feedback.

An online follow-up was completed 8 months later, involving a repeat of the knowledge quiz and a survey asking the participants to reflect on the module's effect on their sepsis management and interprofessional teamwork skills. 


\section{DISCUSSION}

We chose the mixed simulation modalities for two reasons. First, high-fidelity mannequin costs can be prohibitive, and containing cost is important for decreasing barriers to repetitive and deliberate practice, which are the hallmarks of simulation training. ${ }^{7-8}$ Second, high-fidelity simulation, although effective for team behaviours, is not necessarily needed for developing decision-making skills or clinical judgment. ${ }^{9}$ It can also negatively affect learning through overly heightened emotions or cognitive load. ${ }^{10}$ We felt the slower pace and constructivist approach of the RCSim, which may provide a different avenue for deeper learning and consolidation of knowledge.

The learner acceptability of the studied tool was high. Participants found the structure of the module helpful in knowledge and consolidation. This was supported by our finding of a significant improvement in pre- and postknowledge test scores from $75 \%$ to $85 \%$, respectively $(p<0.0001)$. This improvement magnitude was relatively consistent between subspecialties and across years of training. The 8-month follow-up knowledge retention test found no evidence of knowledge decay.

Predominant themes generated from the evaluation and feedback of the program indicated high value for knowledge gain, and improvements in collaborative behaviours. The 8-month follow-up survey found similar lasting value in self-reported collaborative skills and team communication.

As a pilot study, we focused on formative assessment as the major tool to provide deeper learning. We did not use objective measurement scales because behaviour scales are intrinsically task-specific, and we felt that they would be challenging to implement due to the interprofessional nature of the teaching module. We believe that the approach that we used is more flexible in that it would allow various types of health care professionals to use this tool. Technology-enhanced simulation is becoming much more accessible, and, with evidence of improvement in team processes and with focus on patient safety, there is increasingly compelling evidence to use this in the training of our health care trainees and team members.

\section{SUMMARY}

We developed and assessed a module that we feel meets the increasing demand for IPE by using a broadly relevant and high impact medical content of sepsis management.
The module that we developed provides collaborative learning of an interprofessional nature and incorporates reflective practice. It resulted in a high level of acceptability and knowledge retention as well as relative cost-effectiveness. We believe that our sepsis module is an effective way to introduce interprofessional learning that can be easily integrated into any existing postgraduate or continuing medical education curriculum.

Acknowledgements: We thank Angele Landriault and Dr. Joshua Peachey for their invaluable support in running the simulation sessions.

Competing interests: The pilot study was funded, in part, through Pfizer Canada. The funding was granted through the Practice, Performance and Innovation (PPI) branch of the Royal College of Physicians and Surgeons of Canada (RCPSC) with no restrictions. The PPI branch of RCPSC also provided in-kind support for costs of intellectual property through the right to use RCSim.

\section{REFERENCES}

1. Brock D, Abu-Rish E, Chiu C-R, et al. Republished: interprofessional education in team communication: working together to improve patient safety. Postgrad Med 7 2013; 89(1057):642-51.

2. Mundell WC, Kennedy CC, Szostek JH, et al. Simulation technology for resuscitation training: a systematic review and meta-analysis. Resuscitation 2013;84(9):1174-83.

3. Doumouras AG, Keshet I, Nathens AB, et al. A crisis of faith? A review of simulation in teaching team-based, crisis management skills to surgical trainees. 7 Surg Educ 2012; 69(3):274-81.

4. Paige JT, Garbee DD, Kozmenko V, et al. Getting a head start: high-fidelity, simulation-based operating room team training of interprofessional students. $\mathcal{f}$ Am Coll Surg 2014; 218(1):140-9.

5. Hunziker S, Johansson AC, Tschan F, et al. Teamwork and leadership in cardiopulmonary resuscitation. $7 \mathrm{Am}$ Coll Cardiol 2011;57(24):2381-8.

6. Levy MM, Dellinger RP, Townsend SR, et al. The Surviving Sepsis Campaign: results of an international guideline-based performance improvement program targeting severe sepsis. Crit Care Med 2010;38(2):367-74.

7. Zendejas B, Wang AT, Brydges R, et al. Cost: the missing outcome in simulation-based medical education research: a systematic review. Surgery 2013;153(2):160-76.

8. McGaghie WC, Issenberg SB, Petrusa ER, et al. A critical review of simulation-based medical education research: 2003-2009. Med Educ 2010;44(1):50-63.

9. Nyssen A-S, Larbuisson R, Janssens M, et al. A comparison of the training value of two types of anesthesia simulators: computer screen-based and mannequin-based simulators. Anesth Analg (LWW) 2002;94(6):1560-5.

10. Fraser K, Ma I, Teteris E, et al. Emotion, cognitive load and learning outcomes during simulation training. Med Educ 2012;46(11):1055-62. 